\title{
A Survey of Social Support and Coping Style in Middle School Female Teachers in China
}

\author{
Ping Wang ${ }^{1}$, Qiong Dai ${ }^{2}$ \\ ${ }^{1}$ School of Foreign Languages and Literature of Wuhan University, Wuhan University, Wuhan, China; \\ ${ }^{2}$ Maternal Hospital of Hubei Province, Wuhan, China. \\ Email: wangping1013@126.com, daiqiong74@126.com \\ Received May $20^{\text {th }}, 2011$; revised June $8^{\text {th }}, 2011$; accepted June $15^{\text {th }}, 2011$.
}

\begin{abstract}
Objective: It is hypothesized that social support and different coping style would make a difference in people's health. This paper attempts to investigate social support and coping style in middle school female teachers in Wuhan, China. Methods: 1:2 case-control matched study. 300 female teachers as case group, 300 matched male teachers as control group 1 and another 300 matched female workers as another control group. Results: Female teachers got significantly lower score on positive coping and higher negative coping than male teachers. However, they got significantly higher score on positive coping and lower negative coping than female workers $(P<$ 0.05 respectively). Female teachers scored significantly lower than male teachers but higher than female workers on total score of social support, objective and subjective support and utility degree of social support $(P<0.05$ respectively). There were no significant differences between female teachers from senior and junior middle schools on coping style and social support $(P>0.05$ respectively). The female teachers from key senior and junior middle schools got significantly higher score on positive coping style and social support than those from non-key middle schools $(P<0.05$ respectively). There were no significant differences between female teachers on negative coping from key and non-key senior and junior middle schools $(P>0.05$ respectively). The female teachers with a higher title and professional qualification got significantly lower score on negative coping and higher score on positive coping and social support than female teachers with a lower title and professional qualification and female workers $(P<0.05$ respectively). The female teachers with master and bachelor degree got significantly lower score on negative coping and higher score on subjective support and utility degree of social support than those without a degree $(P<0.05$ respectively). Conclusion: The impact of social support and coping style showed significant differences for female teachers of different school, professional and education level.
\end{abstract}

Keywords: Social Support, Coping Style, Middle School, Female Teachers

\section{Introduction}

Teachers' stress is a much discussed issue. However, the research on teachers' (especially female teachers) coping style and social support for different stages of school is insufficient. The American scholar Turner (1983) discussed social support in a systematic way in his book Social support: Conceptualization, measurement, and implication for mental health. Vernitria (2009) discussed about improving teacher retention by providing needed support in her doctorate dissertation. Xie \& Li (2010) discussed the relationship between female teachers' life quality and their coping style in Shaoxin District, China. Lots of papers published abroad and home including Psychological Science, Journal of Personality and Psychology, International Journal of Behavioral Medicine, etc. provided reference for the research of middle school female teachers' way of coping style and social support. Based on a review of international research, it is concluded that teachers' stress is a serious problem and it is definitely associated with a range of causal factors, including those intrinsic to teaching, individual vulnerability and systematic influences.

Female teachers as a special group play not only a teacher's role but also special social roles, such as wife, mother, daughter and so on. China is a country with a long history of feudalism and women are expected to shoulder the duties and response- bilities of service and care giving. It is the usual case that women are the primary care-giver of their families. For some, they are not only the primary care-giver of their nuclear families, but also the extended families as well. Therefore, they have to endure double stress from family and work. As Walkerdine claimed that being a female teacher is actually "an impossible fiction". In Bitter Milk: Women and Teaching, Grumet applies the bitter milk as a metaphor to reveal the paradox of being a female teacher. Indeed, to be a teacher and a primary care-giver of the family are both demanding and it is almost beyond the capacity of a human. Psychosocial factors have been considered largely responsible for the health problems observed in female teachers.

Teachers' job satisfaction has been recognized as extremely important for implementing any type of education reform, for involving the teacher in life-long learning, for the quality of the teaching-learning process, and for satisfaction with life in general. It is of great significance to reduce teachers' stress and increase their job satisfaction. What's more, there may be differences in trait coping style and social support between male and female teachers because females tend to be more delicate and sensitive than males. On the basis of these facts, the study attempts to give a survey of the trait coping style, social support in junior and senior middle school female teachers.

The psychological definition of coping is the process of 
managing taxing circumstances, expending effort to solve personal and interpersonal problems, and seeking to master, minimize, reduce or tolerate stress or conflict (Vitaliano, 1990)

Social support has been summarized as a network of individuals on whom one can rely for psychological or material support to cope effectively with stress. Social support is theorized to be offered in the form of instrumental support (i.e., material aid), appraisal/informational support (i.e., advice, guidance, feedback), or emotional support (i.e., reassurane of worth, empathy, affection) (Turner, 1983) Social support in this paper is mainly concerned with the support related to support to teachers' work and life.

Perceived social support is support that an individual believes to be available, regardless of whether the support is actually available. Actually, perceived support appears to correlate more closely with health status than does actual social support (Edgar \& Rhonda, 2000: p. 920).

Social support is one of the most important factors in predicting the physical health and well-being of everyone, ranging from children to adults. The well-being of people are sustained through primary group ties, the absence of which may result in a loss of identity, confusion and despair (Schwarzer \& Leppin, 1991). In most cases, the absence of social support would harm the physical and mental health among the impacted individuals. The initial social support given is also a determining factor in successfully overcoming the stress in everyday life. The presence of social support significantly predicts the individual's ability to cope with stress. Knowing that they are valued by others is an important psychological factor in helping them to forget the negative aspects of their lives, and thinking more positively about their environment. Social support not only helps improve a person's well-being, it affects the immune system as well (Taylor, et al., 2007). Thus, it is also a major factor in preventing negative symptoms such as depresssion and anxiety (Taylor, 2006). At the same time, the social support and physical health are two of the crucial factors that help the overall well-being of individuals.

\section{Participants}

The study was carried out during 2010-2011 by selecting 320 female teachers randomly from ten junior and senior middle schools in Wuhan urban areas to fill in the questionnaires. 300 questionnaires were collected, reaching a response rate of $93.75 \%$.

Control group was divided into two groups. Control group 1 was an age-stratified random sample of male teachers in the same school and 1:1 frequency-matched to the female teachers within 5-year age groups and adjusted teaching course. Control group 2 was an age-stratified random sample of women in $\mathrm{Wu}-$ han (urban areas) identified by using random digit dialing. Controls were randomly selected and 1:1 frequency-matched to the female teachers within 5-year age groups and adjusted educational years.

\section{Data Collection}

Face-to-face interviews were conducted. Interviewers were trained in survey and mental assessment methods. The same interviewer interviewed both cases and the age-matched con- trols to reduce information bias. Information on demographic characteristics (ethnicity, residence) was ascertained directly from the subjects. All participants were interviewed with traits coping style questionnaire (TCSQ) and social support rating scale (SSRS).

\section{Psychosocial Measures}

Participants completed questionnaires at baseline to assess demographic and psychosocial variables. Questionnaires were administered as following:

Social support was measured by the social support rating scale (SSRS) (Wang, 1999). The SSRS, with10 items, is to assess the scores of objective and subjective support, utility degree of social support, and measures perceived availability (the number of people the individual thinks he or she can count on when necessary) and satisfaction with perceived social support respectively.

Coping style was measured by the trait coping style questionnaire (TCSQ) (Wang, 1999). The TCSQ composed of positive coping and negative coping, and each factor was respecttively composed of 10 items, the scores on coping styles were assessed by the differences between the negative coping and positive coping. The higher the scores, the more negative the coping styles were. The extent to which each item has been experienced is rated on a 5-point scale, ranging from 1 (very positive) to 5 (very negative).

\section{Data Analysis}

All data was carried out by SAS 9.0 software. Descriptive statistics were calculated for all variables. Student $t$ tests (for continuous data), analysis of variance (ANOVA) and Spearman Rank Correlation were used to assess differences between the case and control groups. All tests of statistical significance were two-sided and considered as $p \leq 0.05$.

\section{Results}

Associations between each of the 6 independent variables in 2 independent questionnaires - traits coping style questionnaire (TCSQ scores), and social support rating scale (SSRS scores)were examined separately at the different points of assessment.

\section{Comparison of Female Teachers and National Norm.}

Female teachers scaled significantly higher score on positive coping $(24.47 \pm 4.71)$ than national norm $(21.25 \pm 7.14) . \mathrm{t}=$ $3.31, P=0.001$. (Wang, 1999) Female teachers scaled significantly lower score on negative coping $(12.51 \pm 3.53)$ than national norm $(30.26 \pm 8.74) . \mathrm{t}=5.78, p=0.000$.

Female and male teachers and female workers on the scale of TCSQ and SSRS (Table 1).

Female teachers got significantly lower score on positive coping and higher negative coping than males, however, they got significantly higher score on positive coping and lower negative coping than female workers $(\mathrm{F}=24.576, P<0.05$; $\mathrm{q}_{0.05}=4.77, \mathrm{q}_{0.01}=5.84, P<0.05$ respectively). Female teachers scored significantly lower than male teachers but higher than female workers on total score of social support, objective 
Table 1.

Female and male teachers and female workers on the scale of TCSQ and SSRS.

\begin{tabular}{|c|c|c|c|c|}
\hline Questionnaire & Variable & Case $(n=300)$ & Case $(n=300)$ & Control $2(n=300)$ \\
\hline \multicolumn{5}{|l|}{ TCSQ } \\
\hline & Positive coping & $24.47 \pm 4.71$ & $26.52 \pm 7.40$ & $21.55 \pm 5.22$ \\
\hline & Negative coping & $12.51 \pm 3.53$ & $8.75 \pm 4.45$ & $15.89 \pm 3.89$ \\
\hline \multicolumn{5}{|l|}{ SSRS } \\
\hline & Total score of social support & $40.77 \pm 1.97$ & $43.64 \pm 1.76$ & $35.02 \pm 2.55$ \\
\hline & Objective support & $8.43 \pm 2.22$ & $11.36 \pm 3.49$ & $5.30 \pm 1.76$ \\
\hline & Subjective support & $24.90 \pm 3.85$ & $31.44 \pm 4.67$ & $18.87 \pm 3.12$ \\
\hline & Utility degree of social support & $60.50 \pm 7.97$ & $65.67 \pm 5.77$ & $58.93 \pm 7.78$ \\
\hline
\end{tabular}

and subjective support and utility degree of social support $(\mathrm{F}=$ 13.881, $P<0.05 \mathrm{q}_{0.05}=4.82, \mathrm{q}_{0.01}=5.76, P<0.05$ respectively).

Comparison of female teachers between key and non-key senior and junior middle schools scored on TCSQ and SSRS (Table 2).

There were no significant differences between female teachers from senior and junior middle schools on coping style and social support ( $p>0.05$ respectively). The female teachers from key senior and junior middle schools got significantly higher score than non-key senior and junior middle schools on positive coping style and social support $\left(\mathrm{q}_{0.05}=4.04, \mathrm{q}_{0.01}=5.65, p<\right.$ 0.05 respectively). There were no significant differences between female teachers from both key and non-key senior or junior schools on negative coping $\left(\mathrm{q}_{0.05}=3.26, \mathrm{q}_{0.01}=4.75, P>\right.$ 0.05 respectively).

Comparison of female teachers of different age groups scored on TCSQ and SSRS (Table 3).

There were no significant differences among different age groups of female teachers on coping style and social support ( $p$ $>0.05$ respectively).

Female teachers of different titles scored on TCSQ and SSRS (Table 4).

The female teachers with higher title and qualifications got significantly lower score on negative coping and higher score on positive coping and social support than female teachers with lower title and qualifications and female workers. $\left(\mathrm{r}_{\mathrm{s}}=0.8776\right.$, $P<0.05$ respectively).

Female teachers of different education level scored on TCSQ and SSRS (Table 5).

The female teachers with master and bachelor degree got significantly lower score on negative coping and higher score on subjective support and utility degree of social support than female workers ( $\mathrm{r}_{\mathrm{s}}=0.8043, p<0.05$ respectively).

\section{Discussion}

The result of study showed that female teachers got higher score on positive coping and lower score on negative coping than national norm. In coping with different life events, female teachers are more mature than average groups in the city. There are some differences between female teachers in different schools with different academic titles and qualifications.

To be human is to experience crisis. The reaction to the same crisis differs from one to the other. The emotional experience is as individual as the other characteristics of individuals. The result of this study showed that female teachers got significantly lower score on positive coping and higher negative coping than male teachers, however, they got significantly higher score on positive coping and lower negative coping than female workers. In coping with different life events, male teachers are more mature than female ones. What's more, the result of this study showed that the female teachers of key senior and junior middle schools got significantly higher score than those of non-key senior and junior middle schools on coping style, and that the female teachers with a higher title and professional qualification got significantly lower score on negative coping and higher score on positive coping than female teachers with a lower title and professional qualification and female workers, and that the female teachers with master and bachelor degree got significantly lower score on negative coping than those without master and bachelor degree, and there were no significant differences among different age groups of female teachers on coping style. In coping with pressure, female teachers are able to solve problems by themselves. Specially, female teachers with a high title and degree have more self-independence and better anti-pressure when they have to face difficulties. However, male teachers have better anti-pressure than female teachers. Maybe it is because female teachers need to copy with more household chores besides teaching. At the same time, with the advancement of society and technology as well as the reform and improvement of basic education curriculum, society, school leaders and parents develop higher expectation and demands for teachers including the quality of creative thinking, good humanistic and other excellent qualities. Therefore, teachers should improve themselves constantly in all-round way. Not only female teachers have to face pressure from their work, the assessment of teaching effectiveness, but also they should face the pressure from their academic improvement. Thus, female teachers in middle schools, especially those with lower degree and title could hardly endure additional pressure.

The result of this study showed that female teachers scored significantly lower than male teachers but higher than female workers on total score of social support, objective and subject- 
Table 2.

Comparison of female teachers of key and not key senior and junior schools scored on TCSQ and SSRS $(\bar{x} \pm s)$.

\begin{tabular}{cccccccc}
\hline Questionnaire & Variable & Key Senior school & Senior school & Key junior school & junior school & F & p \\
\hline \multicolumn{1}{c}{ TCSQ } & & & & & & & \\
& & & & & & & \\
& Positive coping & $23.55 \pm 7.75$ & $22.07 \pm 5.34$ & $23.99 \pm 5.98$ & $21.99 \pm 4.97$ & 0.196 & 0.899 \\
& Negative coping & $8.53 \pm 3.24$ & $8.56 \pm 3.11$ & $8.55 \pm 3.12$ & $8.54 \pm 3.07$ & 0.200 & 0.884 \\
SSRS & & & & & & & \\
& & & & & & & \\
& Total score of social support & $46.53 \pm 9.60$ & $40.12 \pm 5.65$ & $47.24 \pm 7.55$ & $40.67 \pm 6.13$ & 12.143 & 0.000 \\
& Objective support & $13.11 \pm 3.44$ & $9.85 \pm 1.20$ & $13.23 \pm 3.03$ & $8.22 \pm 2.43$ & 10.780 & 0.000 \\
& Subjective support & $26.46 \pm 3.14$ & $20.88 \pm 4.07$ & $25.94 \pm 3.33$ & $21.01 \pm 3.21$ & 4.979 & 0.003 \\
& Utility degree of social support & $64.80 \pm 5.11$ & $60.00 \pm 5.98$ & $65.11 \pm 5.67$ & $61.20 \pm 5.76$ & 3.451 & 0.017 \\
\hline
\end{tabular}

Note: when $P<0.05$, SNK test is done.

Table 3 .

Comparison of female teachers of different age groups scored on TCSQ and SSRS $(\bar{x} \pm s)$.

\begin{tabular}{|c|c|c|c|c|c|c|}
\hline Questionnaire & Variable & $\leq 35(\mathrm{y})$ & $36-45(y)$ & $46-55(y)$ & $\mathrm{F}$ & $\mathrm{p}$ \\
\hline \multicolumn{7}{|l|}{ TCSQ } \\
\hline & Negative coping & $8.98 \pm 4.12$ & $9.01 \pm 4.32$ & $8.92 \pm 4.09$ & 0.300 & 0.741 \\
\hline \multicolumn{7}{|l|}{ SSRS } \\
\hline & Scale & $44.53 \pm 7.30$ & $43.12 \pm 6.66$ & $43.29 \pm 7.49$ & 2.155 & 0.134 \\
\hline & Objective support & $12.11 \pm 6.54$ & $11.97 \pm 7.27$ & $12.20 \pm 6.93$ & 1.973 & 0.394 \\
\hline & Subjective support & $23.64 \pm 4.71$ & $22.98 \pm 4.77$ & $22.94 \pm 4.73$ & 3.316 & 0.413 \\
\hline & Utility degree of social support & $63.18 \pm 5.21$ & $62.98 \pm 5.18$ & $63.17 \pm 5.67$ & 0.153 & 0.936 \\
\hline
\end{tabular}

Table 4.

Female teachers of different title scored onTCSQ and SSRS $(\bar{x} \pm s)$.

\begin{tabular}{|c|c|c|c|c|c|}
\hline Questionnaire & Variable & Highest title & High title & Middle title & low title \\
\hline \multicolumn{6}{|l|}{ TCSQ } \\
\hline & Positive coping & $25.58 \pm 9.63$ & $24.79 \pm 8.34$ & $20.11 \pm 7.12$ & $21.02 \pm 8.68$ \\
\hline & Negative coping & $6.35 \pm 6.76$ & $6.56 \pm 7.94$ & $9.63 \pm 6.18$ & $9.54 \pm 7.91$ \\
\hline \multicolumn{6}{|l|}{ SSRS } \\
\hline & Scale & $46.85 \pm 8.60$ & $47.12 \pm 7.67$ & $41.24 \pm 7.59$ & $41.60 \pm 7.31$ \\
\hline & Objective support & $13.74 \pm 1.43$ & $13.73 \pm 2.01$ & $9.01 \pm 1.20$ & $8.78 \pm 1.44$ \\
\hline & Subjective support & $26.68 \pm 3.64$ & $26.34 \pm 3.88$ & $20.67 \pm 3.07$ & $20.59 \pm 3.12$ \\
\hline & Utility degree of social support & $64.79 \pm 6.73$ & $65.19 \pm 6.63$ & $60.91 \pm 5.98$ & $61.20 \pm 5.76$ \\
\hline
\end{tabular}

tive support and utility degree of social support. In China, with the improvement of the social status of teachers, teachers feel more support from family, friends and neighbors. But it can not be ignored that men who are generally considered the more important role in a family have higher degree of concern and more readily support available from family members, especially their wives. Female teachers have to face as intense competition and pressure as male teachers, and take more care of their families. They are busy and have little free time to relax and it causes their psychological imbalance as to impact their rela- 
Table 5 .

Female teachers of different education level scored on TCSQ and SSRS ( $\bar{x} \pm s)$.

\begin{tabular}{|c|c|c|c|c|c|}
\hline Questionnaire & Variables & Master & Bachelor & Junior college & No degree \\
\hline \multicolumn{6}{|l|}{ TCSQ } \\
\hline & Positive coping & $25.15 \pm 8.34$ & $24.97 \pm 8.92$ & $20.12 \pm 8.14$ & $19.92 \pm 8.07$ \\
\hline & Negative coping & $6.00 \pm 4.46$ & $6.16 \pm 4.25$ & $9.09 \pm 5.14$ & $8.93 \pm 6.13$ \\
\hline \multicolumn{6}{|l|}{ SSRS } \\
\hline & Scale & $46.94 \pm 7.61$ & $47.03 \pm 7.59$ & $40.94 \pm 7.67$ & $41.01 \pm 7.61$ \\
\hline & Objective support & $13.35 \pm 1.67$ & $13.36 \pm 2.01$ & $8.97 \pm 1.03$ & $8.87 \pm 1.14$ \\
\hline & Subjective support & $27.32 \pm 3.43$ & $26.84 \pm 3.52$ & $20.16 \pm 3.73$ & $20.21 \pm 3.65$ \\
\hline & Utility degree of social support & $65.33 \pm 6.22$ & $65.24 \pm 6.37$ & $60.19 \pm 5.53$ & $59.97 \pm 5.48$ \\
\hline
\end{tabular}

tionship with their family, colleagues and friends, and it also causes a variety of discontentment. As a result, it is less likely for them to feel the support form their family and community. The result of this study showed that female teachers of key senior and junior middle schools got significantly higher score than non-key female teachers on social support. Parents do hope that their children be admitted to key universities so that teachers in key schools can be the focus of concern from community and feel respected. Teachers in non-key schools have to manage many issues besides teaching by themselves. In addition, the teachers from non-key middle schools endure greater pressure from examinations and academic qualifications than teachers from key middle schools because of the poor basis of the students. The result of this study showed that female teachers with higher title and degree got significantly higher score on social support than female teachers with lower title and degree and female workers. Teachers with higher title and degree are more likely to identify with community, schools and family members. At present, government has begun to adopt the annual appointment policy. Teachers with lower title and degree are very likely to have a sense of insecurity and this add to their physical and mental stress.

A large number of studies have confirmed that a good social support can reduce the individual cognitive appraisal to pressure as to reduce hurt when individual face pressure (Knoll \& Schwarzer et al., 2009). Due to the lack of capacity to negative emotional catharsis, the tensions linked to the strongest emotion convey and derail in the body. The accumulation of repressed negative energy can cause symptoms and psychosomatic diseases. From physiological perspective, social support is to provide emotional support, and then affect the physiological processes related to emotion, and improve the level of individual physical health, as well as to enhance the organism's immunity so as to develop the individual tolerance to frustration and to decrease physical and mental diseases. The sources of social support is only a potential support, "perceived psychological reality is psychological reality as the actual medi-variables to impact human behavior and development" (Schwarzer \& Knoll, 2007). Subjective support is more valued.

In summary, we believe that more attention should be paid to the multi-factor of impact on female teachers' mental health. Therefore, community, schools and families should work to improve female teachers' mental health in middle schools. Based on the occupational characteristics of female teachers in middle schools, educational authorities and schools should offer the corresponding help. For example: to afford continual education to female teachers with lower title and degree, to elevate their professional level so that they can have a sense of self-fulfilment and are easy to identify themselves with community and family. Information support from their colleagues (for example: providing certain necessary knowledge), practical support (for example: helping to complete tasks), as well as emotional support can enhance female teachers' command to the situation in work so as to reduce the level of pressure and depersonalization and to improve the personal achievement and performance (Esther \& Ronald et al., 1997). The society shouldn't hold too high expectation for the teachers and teachers should also have reasonable expectations of themselves because teachers' ability is limited. At the same time, teachers should get opportunity to improve themselves constantly so as to catch up with the advancement of the society. Female teachers in middle schools should be provided regular mental health counseling services to help and guide them to the establishment of good interpersonal relationships and social support networks in order to alleviate mental pressure, improve the mental health, and improve their subjective support and utility degree of social support as well. Female teachers should be encouraged to communicate with leaders, colleagues, family members and friends when they meet difficulties and pressure, and actively set up and take social support in order to overcome difficulties in work and life so as to maintain their physical and mental health.

Our study may have some dismerits as case-control studies are notoriously susceptible to bias. We have tried to reduce sampling bias by recruiting from ten different schools. To reduce reporting and measurement bias, we used two interviewers and ensured that borderline events and difficulties were rated at consensus meetings, and that equivocal stressors were rated by a third person unaware of the objective of study. However, like all case-control studies, it has potential limitations. For example, the results could have been affected by recollection bias because the women were asked to recall past feelings and events. 


\section{References}

Cassel, J. (1976). The contribution of the social environment to host resistence. Journal of Epidemiology, 9, 23-27.

Edgar, F. B., \& Rhonda, J. V. (2000). Encyclopedia of sociology (2nd ed.). New York, NY: Macmillan Reference USA.

Esther, R. G., Ronald, J. B., \& Roman, K. L. (1997). The impact of social support on the development of burnout in teacher: Examination of a model. Work \& Press, 11, 267-781.

Folkman, S., \& Lazarus, R. S. (1988). Coping as a mediator of emotion. Journal of Personality and Social Psychology, 54, 466-475. doi:10.1037/0022-3514.54.3.466

Knoll, N., Schwarzer, R., Fuller, B. et al. (2009). Transmission of depressive symptoms in couples undergoing assisted reproduction treatment. European Psychologis, 14, 5-15.

Luszczynska, A., Boehmer, S., Knoll, N. et al. (2007). Emotional support for men and women with cancer: Do patients receive what their partners provide? International Journal of Behavioral Medicine, 14, 156-163. doi:10.1007/BF03000187

Schwarzer, R., \& Leppin, A. (1991). Social support and health: A theoretical and empirical overview. Journal of Social and Personal Relationships, 8, 99-127. doi:10.1177/0265407591081005

Schwarzer, R., \& Knoll, N. (2007). Functional roles of social support within the stress and coping process: A theoretical and empirical overview. International Journal of Psychology, 42, 243-252. doi:10.1080/00207590701396641

Sukari, L. S. (2006). Support systems that facilitate high school teacher's PADs evaluation ratings. Ph.D. Thesis, Houston, Texas: Texas Southern University.

Taylor, S. E., Welch, W. T., Kim, H. S. et al. (2007). Cultural differences in the impact of social support on psychological and biological stress responses. Psychological Science, 18, 831-837. doi:10.1111/j.1467-9280.2007.01987.x

Taylor, S. E. (2006). Tend and befriend: Biobehavioral bases of affiliation under stress. Current Directions in Psychological Science, 15, 273-277. doi:10.1111/j.1467-8721.2006.00451.x

Turner, R. J., Frankel, B. G., \& Levin, D. M. (1983). Social support: Conceptualization, measurement, and implication for mental health. Greewich, CT: JAI Press.

Vernitria, V. R. (2009). Teacher leadership: Providing needed support to improve teacher retention. Ph.D. Thesis, Minneapolis, MA: Capella University.

Vitaliano, P. (1990). Coping profiles associated with psychiatric, physical health work and family problems. Health Psychology, 9, 343-376. doi:10.1037/0278-6133.9.3.348

Wang, X. (1999). Life event scale. Psychological hygiene assessment scale manual (updated version). Beijing: Chinese Psychological Hygiene Journal Publishing House.

Xie, M., \& Li, L. (2010). The relationship between female teachers' life quality and their coping style-A research based on Shaoxin district. Education Research and Experiment, 1, 88-91. 